\title{
Sink and source co-limitation in the response of stored non-structural carbohydrates to an intense but short drought
}

\author{
Víctor Resco de Dios ${ }^{1,2,3} \cdot$ Arthur Gessler ${ }^{4,5}$
}

Received: 9 March 2021 / Accepted: 10 March 2021 / Published online: 17 March 2021

(c) The Author(s), under exclusive licence to Springer-Verlag GmbH Germany, part of Springer Nature 2021

\begin{abstract}
Key message Understanding the role of stored non-structural carbohydrates (NSC) in trees has been a long-term goal in tree physiology research. A study published in this issue strengthens the possible role of NSC storage as key to mitigate drought effects.
\end{abstract}

Understanding the patterns of storage and use of non-structural carbohydrates (NSCs) has been a long-term goal of tree physiology (Kozlovski and Keller 1966). NSCs account for $\sim 10 \%$ of the total tree dry biomass (Martínez-Vilalta et al. 2016), but why do trees need so much of their carbon stored as NSCs remains unresolved (Resco de Dios et al. 2020).

The traditional debate focused on whether storage is an active process, where plants diverge NSCs from other processes into storage, or a passive one, where only excess NSCs not used for growth and maintenance are stored (Chapin et al. 1990). If storage is active, it then follows that NSCs act like an insurance providing resilience against future stresses or disturbances (Wiley and Helliker 2012). That is, NSCs would provide the building blocks for recovery following fire or drought, for example, and it would be consequently adaptive to prioritize $\mathrm{C}$ allocation to storage over growth and other processes, as a bet hedging strategy to face uncertainty (Galiano et al. 2017). However, a passive storage has sometimes been interpreted as indicative of a

Víctor Resco de Dios

v.rescodedios@gmail.com

1 School of Life Science and Engineering, Southwest University of Science and Technology, Mianyang, China

2 Joint Research Unit CTFC-AGROTECNIO, Universitat de Lleida, Lleida, Spain

3 Department of Crop and Forest Sciences, University of Lleida, Lleida, Spain

4 Ecosystem Ecology, Swiss Federal Research Institute WSL, Zürcherstr. 111, 8903 Birmensdorf, Switzerland

5 Department of Environmental Systems Science, Institute of Terrestrial Ecosystems, ETH Zurich, Universitätstrasse 16, 8092 Zurich, Switzerland surplus of C, where plant growth would only seldom be limited by C (Palacio et al. 2014). Why such disproportionate amounts of resources are invested to NSC storage if they are simply the leftover of other processes could consequently be maladaptive or, at best, the residual byproduct of a process not fully optimized.

Plant C allocation changes under stress (e.g., Joseph et al. 2020) and consequently different pools show different responses in their concentrations of stored NSCs. Recent observations of drought-induced mortality have catalyzed a renewed interest towards better understanding the function and pattern of variation in NSCs across different organs. It was postulated that one of the mechanisms underlying plantinduced mortality was C starvation (McDowell et al. 2008). That is, a lack of stored NSCs for sustaining respiration and other essential functions. However, actual observations of $\mathrm{C}$ starvation in nature are rare, and often restricted to conditions when the plant is putatively C-limited by its environment, such as situations of deep shade (Duan et al. 2013; Korner 2003). In fact, increases in NSC concentrations with drought are not uncommon, although responses vary with species, even closely related ones (Piper 2011).

An increase in NSC concentrations during drought can occur if the decline in source activity (leaf photosynthesis) is larger than the decline in NSC consumption by $\mathrm{C}$ sinks (growth, respiration, etc.), a response that has been associated with drought resistance (Palacio et al. 2014). That is, growth is often the most sensitive process to environmental stress and it is inhibited before photosynthesis or other processes are affected by drought (Hsiao et al. 1976). The discussion of sink $v s$. source controls has often been dominated by a $\mathrm{C}$-centric perspective, meaning that $\mathrm{C}$ metabolism (i.e., photosynthesis vs. growth and respiration) has often been viewed as the major control of NSC dynamics (Aspinwall 
et al. 2018). However, NSCs are also important regulators of the plant's water balance as they provide the osmotic protectants necessary to maintain turgor (Sapes et al. 2020; Sevanto et al. 2014).

A new study from Santos et al. (2021) in this issue sheds new light on the roles of sink and source activities, and contrary to expectation, they show that NSC concentration increases in both, sink (leaves) and source (roots) tissues, with drought. Through careful wording, the authors avoided the heated debate on whether allocation to storage is an active or passive process. This does not diminish the value of the study as they provided novel information on the function of stored NSCs by examining the short-term dynamics of NSC concentrations across different pools as drought intensity increased.

The relevance of sink vs. source processes in controlling the plant's $\mathrm{C}$ balance can be partitioned by examining the temporal patterns of metabolic activity and of NSC concentrations across source (leaves) and sink (roots) tissues (Gessler and Grossiord 2019; Hagedorn et al. 2016). According to this model, drought responses under source control (Fig. 1a) should lead first to a decrease in the metabolic activity of source tissues (i.e., leaf photosynthesis) that would decline assimilate availability in the leaves, and over the long term, also in the roots (sinks). However, under sink control (Fig. 1b), a drought-mediated decline in root metabolic activity should initially lead to an increase in the concentrations of root NSC. This increase in turn causes reduced phloem transport from source tissues (Hagedorn et al. 2016) and subsequently, to an acclimative downregulation of photosynthetic activity (Gavito et al. 2019).

Santos et al. (2021) showed a more complex response (Fig. 1c). They followed the dynamics in gas exchange and
NSC concentrations after withholding water for two weeks, until the point of stomatal closure in Cenostigma pyramidale, a woody legume native to the Brazilian Caatinga. They observed that the decline in photosynthesis was the first response to water shortage, occurring after 9-11 days of withholding water. However, changes in NSC concentrations lagged behind those in photosynthesis and increased only after stomatal closure had been reached, 13-15 days after treatment implementation. They report that NSC concentrations in both, roots and leaves, increased particularly because of soluble sugars, which were 2-3 times more common in this species than starch.

Why did NSC concentrations increase in both, leaves and roots? C. pyramidale is deciduous: it will eventually shed its leaves under very intense water scarcity, and before reaching that point, nutrients and stores will presumably be used or mobilized to other tissues. The increase in leaf NSC reported by Santos et al. (2021) is thus likely a transient response (Chuste et al. 2019) and it could lead to a better resistance to water stress as NSCs are involved in osmotic adjustment and provide precursors for various other osmoprotectants.

The increase in root NSC has been more commonly reported and it could be related to the provisioning of reserves for stress recovery after the drought or for leaf sprouting in subsequent seasons. Ouyang et al. (2021) observed such an increase in root NSC (and especially in sugars) after long-term drought as well as a reduction of NSC concentration after rewetting in downy oak, the latter most likely due to the use of root NSC for the production of new tissues. Overall, Santos et al. (2021) reported an increase in NSC in roots and leaves, which are the plant organs that are usually most susceptible to drought. That is, stems are often more resistant to drought-induced cavitation
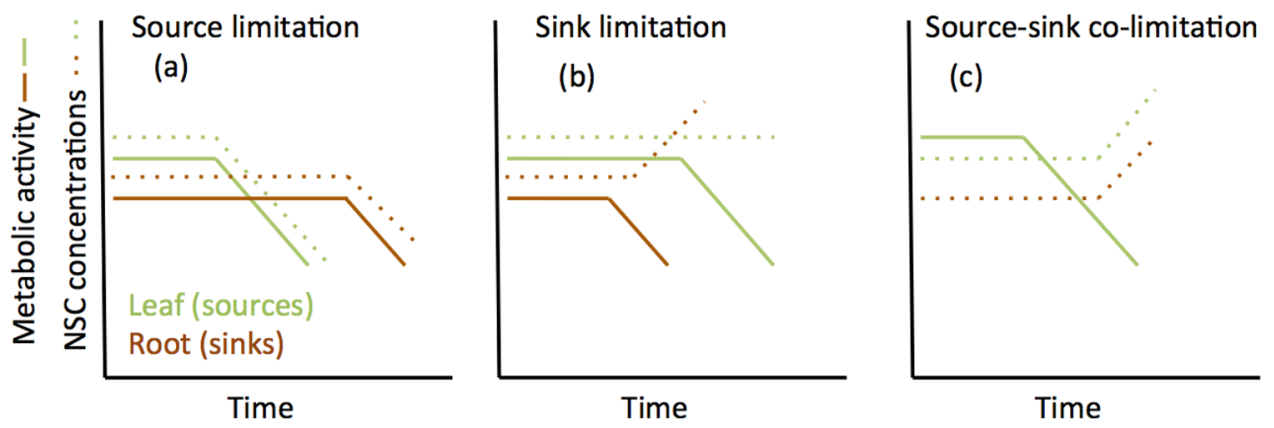

Fig. 1 Under drought stress, we might expect (a) source limitation, (b) sink limitation or (c) sink-source co-limitation. Under source limitation (a), photosynthesis stops first in response to the drought, which then leads to declines in leaf NSC and also to lagged declines in sink tissues. Under sink limitation (b), drought affects root metabolic activity (respiration, growth) first, leading to increased NSC accumulation in roots because photosynthesis continues unchanged but root metabolic demand has declined. Feedback processes lead to a decline photosynthesis later on. Santos et al. (2021) report a different response (c) as photosynthesis stops first in response to drought, and there is a lagged increase in root and leaf NSC concentration. Root metabolic activity was not measured but it is likely to have declined at the same time as in leaves, leading to the co-limitation and explaining the increase in root NSC. The increase in leaf NSC after a decline in photosynthesis is more difficult to explain and it may result from decreased metabolic demand and enhanced need for osmoticants. Panels a and b have been modified from Hagedorn et al. (2016) 
and the dynamic pattern of NSC with drought could consequently be viewed as an active effort, or a passive response, to diminish drought effects on the most vulnerable organs.

A limitation in the study was that the authors did not measure root metabolic activity, and consequently, we cannot know at which point it started to decline. It is, however, likely that the decline in root metabolic activity preceded (and led to) the increase in root NSC concentrations (Fig. 1c). While the lack of data on root respiration means that we cannot conclusively know whether the response was driven by sink or by source processes, it is likely that sink and source limitations arose concomitantly (Fig. 1c). Despite this, the study of Santos et al. (2021) provides an important contribution in its own right and it also leaves unresolved issues for future studies. Some of these include: why do NSC concentrations in source organs increase after photosynthesis decreases?; to which degree are leaf hydraulics and NSC linked (Blackman et al. 2016)?; why, even under conditions of extreme drought, having higher larger stored NSC concentrations does not necessary lead to enhanced survival (Gattmann et al. 2021)?; or why are NSC stores only seldom depleted under extreme drought (Duan et al. 2013), if they provide the sources for osmotic protectants?. Solving these questions will yield sweet results, that will enhance our understanding of trees structure and function.

Acknowledgements VRD acknowledges funding from the National Natural Science Foundation of China (No. 31850410483), the talent funds of Southwest University of Science and Technology (No. 18ZX7131) and the Spanish MICINN (AGL2015-69151-R, RTI2018094691-B-C31). AG acknowledges support from the Swiss National Science Foundation (10030_189109).

Author contribution VRD wrote the manuscript with help from AG.

\section{References}

Aspinwall MJ, Blackman CJ, de Dios VR, Busch FA, Rymer PD, Loik ME, Drake JE, Pfautsch S, Smith RA, Tjoelker MG, Tissue DT (2018) Photosynthesis and carbon allocation are both important predictors of genotype productivity responses to elevated $\mathrm{CO} 2$ in Eucalyptus camaldulensis. Tree Physiol 38:1286-1301

Blackman CJ, Aspinwall MJ, Resco de Dios V, Smith R, Tissue DT (2016) Leaf photosynthetic, economics and hydraulic traits are decoupled among genotypes of a widespread species of eucalypt grown under ambient and elevated $\mathrm{CO}_{2}$. Funct Ecol 30:1491-1500

Chapin FS, Schulze E-D, Mooney HA (1990) The ecology and economics of storage in plants. Ann Rev Ecol Syst 21:423-447

Chuste P-A, Maillard P, Bréda N, Levillain J, Thirion E, Wortemann R, Massonnet C (2019) Sacrificing growth and maintaining a dynamic carbohydrate storage are key processes for promoting beech survival under prolonged drought conditions. Trees Struct Funct 34:381-394

Duan H, Amthor JS, Duursma RA, O'Grady AP, Choat B, Tissue DT (2013) Carbon dynamics of eucalypt seedlings exposed to progressive drought in elevated $\left[\mathrm{CO}_{2}\right]$ and elevated temperature. Tree Physiol 33:779-792

Galiano L, Timofeeva G, Saurer M, Siegwolf R, Martínez-Vilalta J, Hommel R, Gessler A (2017) The fate of recently fixed carbon after drought release: towards unravelling $\mathrm{C}$ storage regulation in Tilia platyphyllos and Pinus sylvestris. Plant Cell Environ 40:1711-1724

Gattmann M, Birami B, Nadal Sala D, Ruehr NK (2021) Dying by drying: timing of physiological stress thresholds related to tree death is not significantly altered by highly elevated $\mathrm{CO}_{2}$. Plant Cell Environ 44:356-370

Gavito ME, Jakobsen I, Mikkelsen TN, Mora F (2019) Direct evidence for modulation of photosynthesis by an arbuscular mycorrhiza-induced carbon sink strength. New Phytol 223:896-907

Gessler A, Grossiord C (2019) Coordinating supply and demand: plant carbon allocation strategy ensuring survival in the long run. New Phytol 222:5-7

Hagedorn F, Joseph J, Peter M, Luster J, Pritsch K, Geppert U, Kerner R, Molinier V, Egli S, Schaub M, Liu J-F, Li M, Sever K, Weiler M, Siegwolf RTW, Gessler A, Arend M (2016) Recovery of trees from drought depends on belowground sink control. Nat Plants 2:16111

Hsiao T, Acevedo E, Fereres E, Henderson D (1976) Water stress, growth, and osmotic adjustment. Phil Trans Roy Soc B: Biol Sci 273:479-500

Joseph J, Gao D, Backes B, Bloch C, Brunner I, Gleixner G, Haeni M, Hartmann H, Hoch G, Hug C, Kahmen A, Lehmann MM, Li M-H, Luster J, Peter M, Poll C, Rigling A, Rissanen KA, Ruehr NK, Saurer M, Schaub M, Schönbeck L, Stern B, Thomas FM, Werner RA, Werner W, Wohlgemuth T, Hagedorn F, Gessler A (2020) Rhizosphere activity in an old-growth forest reacts rapidly to changes in soil moisture and shapes whole-tree carbon allocation. Proc Natl Acad Sci 117:24885-24892

Korner C (2003) Carbon limitation in trees. J Ecol 91:4-17

Kozlovski TT, Keller T (1966) Food relations in woody plants. Bot Rev 32:293-382

Martínez-Vilalta J, Sala A, Asensio D, Galiano L, Hoch G, Palacio S, Piper FI, Lloret F (2016) Dynamics of non-structural carbohydrates in terrestrial plants: a global synthesis. Ecol Monog $86: 495-516$

McDowell N, Pockman WT, Allen CD, Breshears DD, Cobb N, Kolb T, Plaut J, Sperry J, West A, Williams DG, Yepez EA (2008) Mechanisms of plant survival and mortality during drought: why do some plants survive while others succumb to drought? New Phytol 178:719-739

Ouyang S, Gessler A, Saurer M, Hagedorn F, Gao D-C, Wang X-Y, Schaub M, Li M-H, Shen W-J, Schönbeck L (2021) Root carbon and nutrient homeostasis determines downy oak sapling survival and recovery from drought. Tree Physiol 3:10-23

Palacio S, Hoch G, Sala A, Körner C, Millard P (2014) Does carbon storage limit tree growth? New Phytol 201:1096-1100

Piper FI (2011) Drought induces opposite changes in the concentration of non-structural carbohydrates of two evergreen Nothofagus species of differential drought resistance. Ann For Sci 68:415-424

Resco de Dios V, Arteaga C, Peguero-Pina JJ, Sancho-Knapik D, Qin H, Zveushe OK, Sun W, Williams DG, Boer MM, Voltas J, Moreno JM, Tissue DT, Gil-Pelegrin E (2020) Hydraulic and photosynthetic limitations prevail over root non-structural carbohydrate reserves as drivers of resprouting in two Mediterranean oaks. Plant Cell Environ 43:1944-1957

Santos M, Barros V, Ls L, Frosi G, Santos MG (2021) Whole plant water status and non-structural carbohydrates under progressive drought in a Caatinga deciduous woody species. Trees Struct Funct 1:10-34 
Sapes G, Demaree P, Lekberg Y, Sala A (2020) Plant carbohydrate depletion impairs water relations and spreads via ectomycorrhizal networks. New Phytol 229:3172-3183

Sevanto S, Mcdowell NG, Dickman LT, Pangle R, Pockman WT (2014) How do trees die? A test of the hydraulic failure and carbon starvation hypotheses. Plant Cell Environ 37:153-161

Wiley E, Helliker B (2012) A re-evaluation of carbon storage in trees lends greater support for carbon limitation to growth. New Phytol 195:285-289
Publisher's Note Springer Nature remains neutral with regard to jurisdictional claims in published maps and institutional affiliations. 